\title{
Diffuse idiopathic skeletal hyperostosis in ancient clergymen
}

\author{
J. J. Verlaan · F. C. Oner · G. J. R. Maat
}

Received: 28 November 2006/Revised: 24 January 2007/Accepted: 26 February 2007/Published online: 28 March 2007

(C) Springer-Verlag 2007

\begin{abstract}
Diffuse idiopathic skeletal hyperostosis (DISH) is a common but often unrecognized systemic disorder observed mainly in the elderly. DISH is diagnosed when the anterior longitudinal ligament of the spine is ossified on at least four contiguous spinal levels or when multiple peripheral enthesopathies are present. The etiology of DISH is unknown but previous studies have shown a strong association with obesity and insulin-independent diabetes mellitus. DISH can lead to back pain, dysphagia, myelopathy, musculoskeletal impairment and grossly unstable spine fractures after minor trauma. In archeological studies a high prevalence of DISH has been demonstrated in ancient clergymen. The present study describes the pathological changes of human remains excavated from the abbey court (Pandhof) in the city of Maastricht, The Netherlands. Human remains of 51 individuals buried between 275 and 1795 CE were excavated and examined. The remains were investigated according to a standardized physical anthropological report and individuals demonstrating ossification of spinal ligaments and/or multiple peripheral enthesopathies were included in the study group. The authors reviewed all available material and after reaching consensus, each abnormality found was given a diagnosis and subsequently recorded. After examination, 28 individuals were considered to be adult males; 11 adult females; three adults of indeterminate sex and nine individuals were of sub adult age. The mean age at death for
\end{abstract}

J. J.Verlaan $(\varangle) \cdot$ F. C. Oner

Department of Orthopaedics, University Medical Center Utrecht, Heidelberglaan 100, 3584 CX Utrecht, The Netherlands e-mail: jj.verlaan@wxs.nl

G. J. R. Maat

Barge's Anthropologica, Leiden University Medical Center, Leiden, The Netherlands adults was 36.8 years. Seventeen adult individuals (40.4\% of all adults), displayed ossifications of at least four contiguous spinal levels and/or multiple enthesopathies of the appendicular skeleton and were therefore, assigned the diagnosis DISH. The mean age of these individuals was $49.5 \pm 13.0$ years. In at least three of these individuals, DISH had led to extensive ossification and subsequent ankylosis of axial and peripheral skeletal structures. In this population of (presumably) clergymen and high-ranking citizens, DISH was observed in unusual high numbers at a relatively young age. Some of the examined cases suggest that DISH may be a seriously incapacitating disorder when the more advanced stages of the disease have been reached. It is hypothesized that "a monastic way of life" can predispose to DISH. Present demographic trends in obesity and diabetes mellitus as potential co-factors for the development of DISH warrant further study to investigate its future prevalence.

Keywords Diffuse idiopathic skeletal hyperostosis . Osteoarchaeology $\cdot$ Paleopathology $\cdot$ Spinal ankylosis

\section{Introduction}

Diffuse idiopathic skeletal hyperostosis (DISH) is a common but often unrecognized systemic disorder observed mainly in the elderly [1]. DISH is diagnosed when ossification of the anterolateral aspect of the anterior longitudinal ligament is present on at least four contiguous spinal levels without involvement of the intervertebral disk space and/or apophyseal (facet) joints [2]. The disease can manifest itself also at extraspinal locations leading to peripheral entheseal ossification and bony spurs [3, 4]. Studies investigating the demographic characteristics of 
DISH have found a prevalence ranging from $2.9 \%$ in the Korean population, to $10.0 \%$ in a Caucasian population with a male/female ratio of $2: 1$ in most investigations [5, 6]. All papers pertinent to DISH demonstrate a consistent and marked increase of the disease with advancing age [7]. Its etiology is unknown but several publications have found correlations with metabolic disorders, especially high body mass index and insulin-independent diabetes mellitus [810]. The difference in prevalence between ethnic groups also suggests genetic factors being involved in the etiology of the disorder $[5,6,11]$.

From paleopathological studies it becomes apparent that DISH is not a disorder from recent history. Its features have for example been demonstrated in the excavated remains of an Italian female individual who lived six centuries CE (Common Era); in the Egyptian pharaoh Ramses II (1302$1213 \mathrm{BCE}$ ); and in hominid specimens as old as the Neandertal Shanidar I living approximately 50,000 years ago [12-15]. Signs of DISH have even been shown in dinosaurs [16]. Although the radiological manifestations of DISH can sometimes be quite dramatic, displaying extensive ossification of ligamentary structures, its clinical symptoms are usually relatively mild [17]. Some authors have described severe dysphagia, progressive airway obstruction, obstructive sleep apnea and difficult endotracheal intubation due to anterior cervical bony protuberances while others have noted minor stiffness or mild pain when the abnormalities were located in the thoracic or lumbar spine $[18,19]$. The presence of DISH has been associated with unstable spinal fractures, often complicated by permanent neurological deficit, following minor trauma $[20,21]$. Still other studies could not confirm these findings and concluded that DISH is a strict radiological observation without clinical relevance $[22,23]$. Presently, medical or surgical intervention is considered necessary for symptomatic treatment in rare cases only.
The "Onze Lieve Vrouwe" Church (OLVK; Church of Our Lady) in Maastricht is one of the oldest churches in The Netherlands with some parts of its structure dating back to the eleventh century [24]. It was built on the foundation of an early medieval Merovingian Church, which in turn was built on the remains of a Roman fortress. When an architectural rearrangement was planned for its garden, the abbey court ('Pandhof') of the OLVK was temporarily available for archaeological investigation. Following initial fieldwork it was discovered that part of the 'Pandhof' had been used as a burial place (Fig. 1) [25]. After excavation and archaeological investigation was completed, the human remains of 51 individuals were sent to our department for physical anthropological examination. During this examination, an unusual high number and particularly strong expression of DISH was noted in the skeletal material with some individuals demonstrating severe ossification of spinal ligaments and multiple peripheral enthesopathies. In this study individuals with DISH are presented to demonstrate its high prevalence and describe some aspects of the wide range of abnormalities resulting from the disease. Furthermore, three cases are highlighted to demonstrate some of the specific musculoskeletal pathology.

\section{Methods}

An archaeological investigation of the Pandhof site was performed and the artifacts found were dated by stratigraphy (dating based on geological superposition of artifacts), and/or seriation (dating using the change of 'fashion' of artifacts over time to estimate the year of burial). After completion of the archaeological examination the excavated human remains were packed individually and sent to our department. After the bones of each individual were
Fig. 1 Photograph of the excavation at the Onze Lieve Vrouwe Kerk in the city of Maastricht

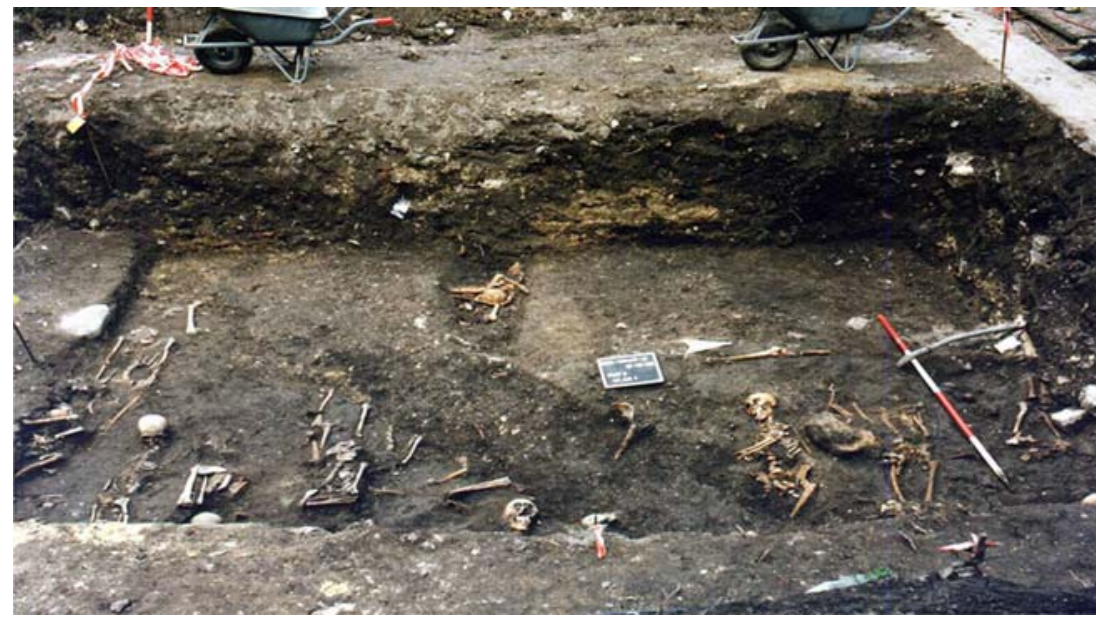


reconstructed, the joints were articulated and the human remains investigated according to a standardized physical anthropological report [26]. For all excavated individuals, attempts were made to assess sex, age at death and stature. Subsequently, they were examined for pathological conditions and individuals demonstrating spinal ligament ossifications of four or more contiguous vertebral levels and/or extensive peripheral enthesopathies were included in the study group [3]. Two authors reviewed all available material and after reaching consensus, each abnormality found was given a diagnosis and recorded. Furthermore, all archaeological records were retrieved to obtain information about estimated year of burial and possible clues to social status or identification.

\section{Results}

A total of 56 graves were discovered during excavation, five of which were empty leaving 51 individuals for investigation. After archaeological examination, the period of burials was determined to be between 275 and 1795 CE [25]. The completeness of the skeletons ranged from poor to good, while the preservation of bone tissue was moderate to good. After examination of all 51 individuals, 28 were considered to be adult males; 11 were adult females; three adults were of indeterminate sex and nine individuals were of sub adult age. The mean age at death of adults was $36.8 \pm 15.9$ years, with a range of 20-69 years, based on $N=38$ comprising of 27 males, eight females and three individuals of indeterminate sex. Seventeen adult individuals $(17 / 42=40.4 \%$ of the adult population; ten males, five females and two individuals of indeterminate sex) displayed key features of DISH (ossification of spinal longitudinal ligaments without involvement of disk space/facet joints and/or the presence of multiple peripheral enthesopathies) and were included in the study group. The individuals diagnosed with DISH had been buried in the interval 450-1795 CE. The mean age of these individuals was $49.5 \pm 13.0$ years with a range of $23-$ 69 years. Table 1 lists the demographic characteristics of individuals from the study group and their specific pathologic conditions.

Three individuals, from grave 25, 43 and 44 are illustrative examples of DISH and are presented in more detail below.

\section{Case grave 25}

The individual in grave 25 was a 47 to 63 -year-old male with healed rib fractures (left side fourth and fifth ribs) and vertebral osteoarthritis. Ossification of the anterior longitudinal ligament at multiple thoracic and lumbar levels,

Table 1 Characteristics of 17 individuals with diffuse idiopathic skeletal hyperostosis

\begin{tabular}{|c|c|c|c|c|}
\hline Grave number & $\begin{array}{l}\text { Age interval } \\
\text { (years) }\end{array}$ & $\begin{array}{l}\text { Estimated age } \\
\text { (years) }\end{array}$ & Sex & Miscellaneous pathologic conditions \\
\hline 1 & 57 & 57 & M & Occipital prominence \\
\hline 4 & $35-55$ & 45 & M & $\begin{array}{l}\text { Spina bifida occulta S1; sacralization L5; ossification of acetabular labrum; } \\
\text { osteochondritis dissecans knee }\end{array}$ \\
\hline 6 & 69 & 69 & $\mathrm{~F}$ & Calcanear spurring; iliac whiskering; torus palatinus \\
\hline 8 & $40-60$ & 50 & M & Vertebral osteophytosis \\
\hline 11 & $>17$ & NK & M & Calcanear spurring \\
\hline 13 & $23-40$ & 32 & I & Calcanear spurring \\
\hline 17 & $40-80$ & 60 & $\mathrm{~F}$ & Osteochondritis dissecans; rachitis; iliac whiskering; occipital prominence \\
\hline 25 & $47-63$ & 55 & M & $\begin{array}{l}\text { Vertebral osteoarthritis; healed fractured ribs (left Th4, Th5); } \\
\text { ossification of glenohumeral soft tissues; extensive ankylosis of thoracic cage }\end{array}$ \\
\hline 27 & $30-60$ & 45 & M & Vertebral osteophytosis; olecranon tufting \\
\hline 29 & $26-35$ & 31 & M & $\begin{array}{l}\text { Calcanear spurring; iliac whiskering; ossification of ischial } \\
\text { tubercle / origo of femoral muscle / iliolumbal ligament / glenoid labrum }\end{array}$ \\
\hline 30 & $51-62$ & 57 & $\mathrm{~F}$ & \\
\hline 41 & $>18$ & NK & I & Allen's fossa; interosseous membrane; patellar tufting \\
\hline 43 & $48-56$ & 52 & M & Bilateral osteomyelitis tibia and fibula; vertebral osteophytosis \\
\hline 44 & 57 & 57 & $\mathrm{~F}$ & Sacralization L5; osteochondritis dissecans of left shoulder and left knee \\
\hline 45 & $40-80$ & 60 & M & Cervical vertebral osteophytosis \\
\hline 47 & $22-24$ & 23 & M & Avulsion fracture Th8; fracture phalanx digit I; olecranon tufting \\
\hline 49 & $>15$ & NK & $\mathrm{F}$ & Calcanear spurring \\
\hline Mean & & 49.5 & & \\
\hline
\end{tabular}

$\mathrm{M}$ male, $\mathrm{F}$ female, I indeterminate sex, NK not known 
except for the part where the aorta is located, confirmed the diagnosis DISH (Fig. 2a, b). It is interesting to note that in rare cases of DISH in individuals with situs inversus, ossification of the anterior ligament is located on the contralateral side supporting the hypothesis that aorta pulsation may prevent ligament ossification [27]. In this individual, ossification of the ligamentum flavum and partial ossification of the interspinal ligament and supraspinal ligament was also seen (Fig. 2c, d). Although some osteophytosis was present at the anterior margin of the vertebral bodies of the thoracic and lumbar spine, no other signs of spinal degenerative changes such as intervertebral or apophyseal joint space narrowing were observed. Extraspinal manifestations of DISH were seen on the right and left humerus where the subscapular muscle insertion had become ossified (Fig. 2e). The sternocostal and sternoclavicular ligaments were ossified leading to a sternum with multiple ribs attached, who on their turn, were at the time of excavation still rigidly attached to the thoracic spine (Fig. 2f). In this individual, extensive ossification of numerous cranial, axial and peripheral muscle insertions was also observed.

\section{Case grave 43}

In grave 43 , a male 48 to 56 years-old-had been buried. DISH was established by the ossification of the anterior longitudinal and supraspinal ligament (Fig. 3a), at multiple levels of the thoracic spine. This part of the spine had subsequently become ankylotic without involvement of the
Fig. 2 Photographs of skeletal remains from a 47 to 63 -yearold male (grave 25) showing: a frontal view of the thoracic spine with obvious ossification of the anterior longitudinal ligament except at the trajectory of the aorta; $\mathbf{b}$ a coronal multiplanar reformatted view from a CT scan demonstrating the same anterior ligament ossification and preservation of most disk spaces; $\mathbf{c}$ the same archaeological specimen from a lateral viewpoint demonstrating the extensive ossification of all ligamentary structures; $\mathbf{d}$ the corresponding sagittal multiplanar reformatted view from a CT scan. Note also the flavum ligament ossification (arrows) and unaffected facet joints; e the left humeral head with ossified insertion of the subscapular muscle at the minor tubercle (arrow); f the sternum with signs of extensive ankylosis and both first ribs attached
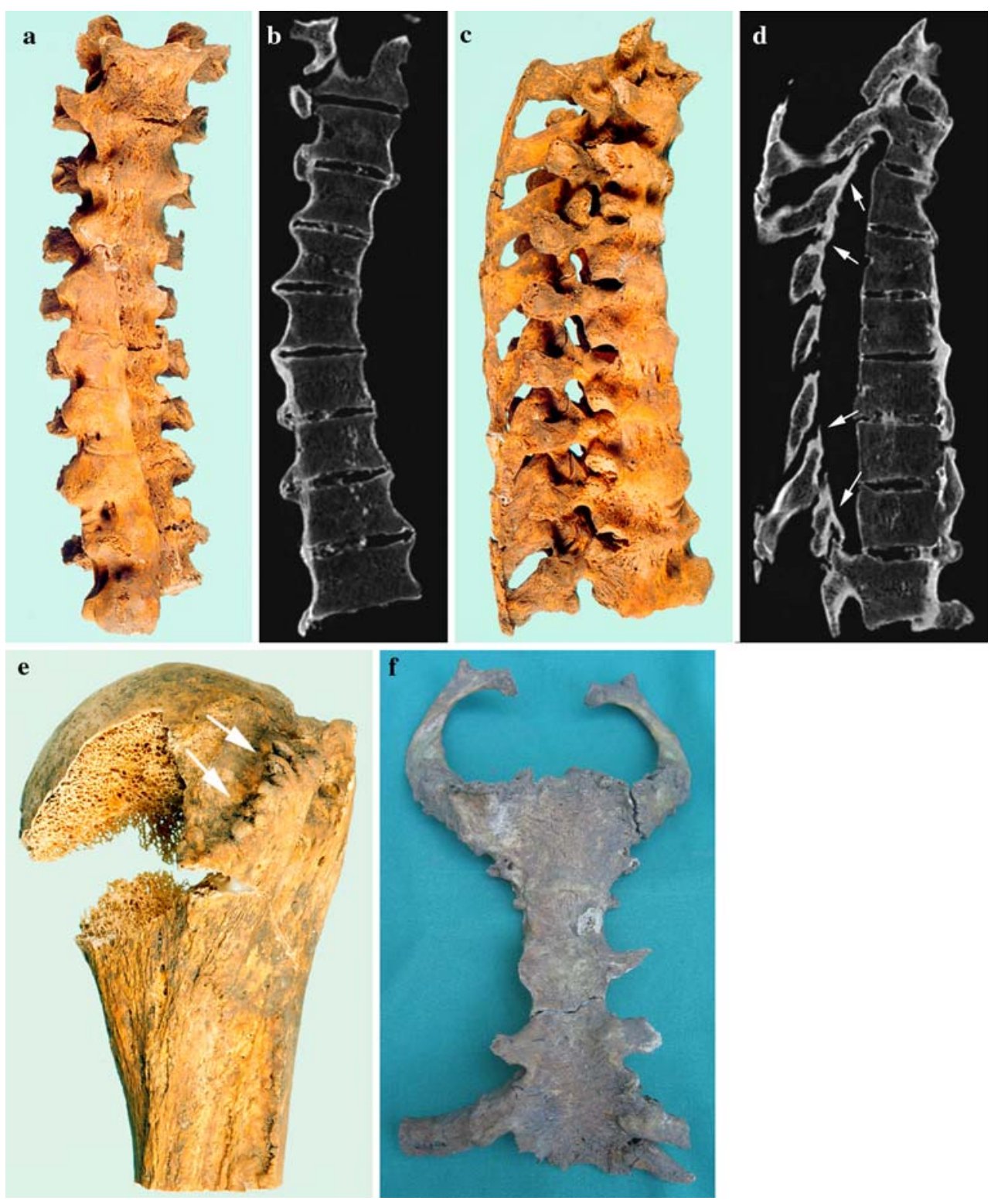


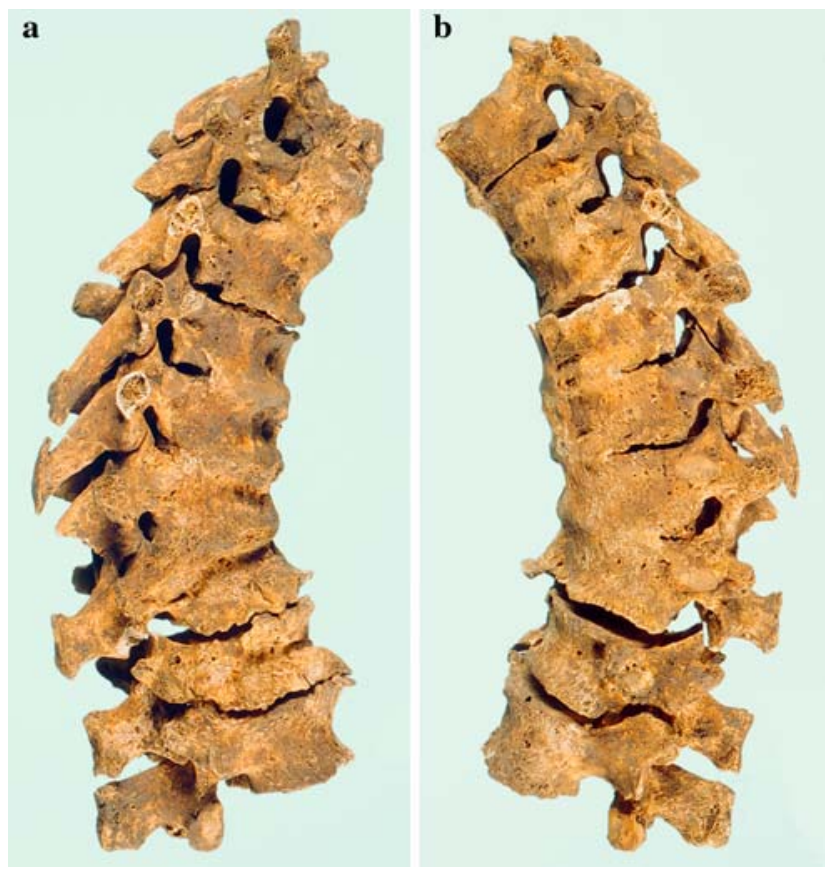

Fig. 3 Photographs of skeletal remains from a 48 to 56 year-oldmale (grave 43) showing: a a right sided lateral view of the thoracolumbar spine with ossification of the anterior longitudinal ligament, vertebral osteophytosis and collapse of the tenth and eleventh thoracic vertebral bodies leading to considerable kyphosis; b the same specimen viewed from the left lateral side

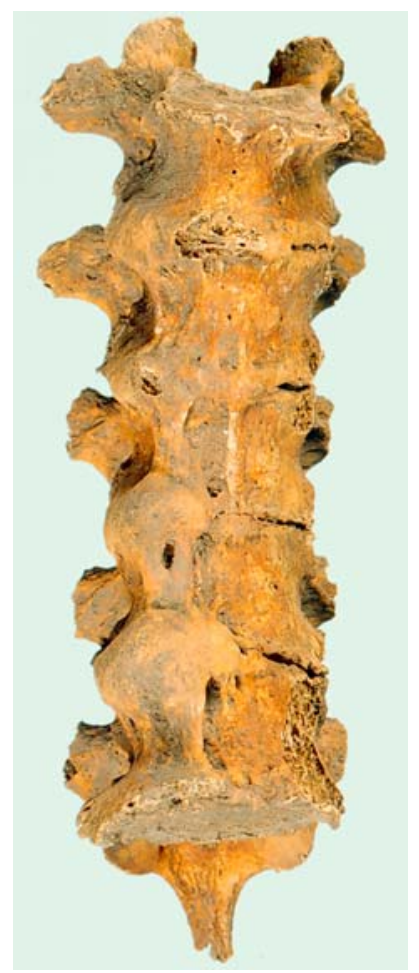

Fig. 4 Photograph of skeletal remains from a 57 year-old-female (grave 44) showing ossification of the anterior longitudinal ligament exhibiting the typical 'flowing wax' phenomenon intervertebral and facet joints. Collapse of the tenth and eleventh thoracic vertebral bodies (probably from traumatic origin), had led to a considerable kyphotic deformity (Fig. 3b). This individual also had bilateral osteomyelitis of both tibia and fibula.

Case grave 44

A 57 year-old-female was buried in grave 44 . This individual showed sacralization of the fifth lumbar vertebra and osteochondritis dissecans of the left glenohumeral joint and the left knee joint. DISH was diagnosed by multiple level ossification of the anterior longitudinal ligament at the thoracic level, which showed the typical 'flowing wax' phenomenon known from clinical radiological examinations (Fig. 4).

\section{Discussion}

Diffuse idiopathic skeletal hyperostosis (DISH) was first described by Forestier [28] in the early fifties and subsequently named after him. When it became clear that peripheral enthesopathies frequently accompanied spinal pathology, suggesting a systemic skeletal condition instead of an isolated spinal disease, the name was changed into diffuse idiopathic skeletal hyperostosis to better describe the wide range of abnormalities possible [29]. DISH can be distinguished from other ankylosing diseases such as ankylosing spondylitis (Morbus Von Bechterew), because bony joints, especially the sacroiliac joints are by definition preserved in DISH [4].

Ossification of the posterior longitudinal ligament (OPLL) is a disease probably strongly related to DISH and has been studied in depth especially in Japan where it is a common condition [30]. Inamasu et al. [31] suggest from their literature review of previously conducted research on OPLL that it is probably not a single-gene disease; that pathways by which osteogenic induction of spinal ligament cells might occur are as yet poorly understood and that bone synthesis marker concentrations have not differed significantly from control groups. It is currently unknown whether the results obtained from research on OPLL may be applicable to DISH as well [30].

In the population excavated from the 'Pandhof' of the OLVK in the city of Maastricht, DISH was the most frequently encountered pathology. Seventeen individuals with an average age at death of 49.5 years were diagnosed with this condition on the basis of spinal ligament ossification or multiple peripheral enthesopathies. The percentage of adult individuals with DISH therefore, was $40.4 \%$. This is an unusual high percentage of DISH in a relatively young population compared to results from radiological studies in 
the literature $[7,11]$. In the study by Rogers and Waldron [32], DISH was found to be present in $11.5 \%$ (6 out of 52 excavated males), of the population buried in the church and chapels from The Royal Mint Medieval site in London while the prevalence of DISH in a nearby lay cemetery where the general population (likely to be peasants/farmers), was buried, was $0 \%$ (0 out of 99 males). They suggested this difference in prevalence $(11.5$ vs. $0 \%)$ to be caused by a difference in occupation and access to food [33]. In the present study the prevalence of DISH was almost fourfold that reported by Rogers and co-authors. Janssen and Maat [34], found in their paleopathological study DISH to be present in $100 \%$ of the inspected clergymen $(N=27$, with a mean age of 56 years ranging from 43 to 75 years and living between 1070 and $1521 \mathrm{CE}$ ) excavated from the Saint Servaas Basilica also in the city of Maastricht. Since the present study group has in common with the clergymen from the Saint Servaas Basilica that the individuals were probably enjoying a high status (as can be concluded from the location of their burial within the confines of the church normally reserved for priests, monks and high-status citizens), and likely had plentiful supply of food, it is not unreasonable to suggest that the associated 'monastic way of life', a term coined by Rogers and Waldron [32], may have predisposed to DISH $[33,35]$. From descriptions of the dietary habits of monks in the Middle Ages in the discussion section of the Rogers article, it can be argued that saturated (animal-) fats combined with small portions of vegetables and ample alcoholic beverages may have often been on the menu, not unlike the diet of a considerable part of modern Western society. The 17 individuals with DISH from the present study were buried in the interval 450-1795 CE. Therefore, it is hypothesised that the interred of the OLVK (and the Merovingian Church before that), may in general have had an abundant food supply during this time period. Although genetic factors may play an important role in the etiology of DISH, to our best knowledge, no historical evidence suggests a closer genetical relationship between monks than between the general population and monks, therefore, a genetical predisposition for monks to develop DISH cannot be demonstrated. From current research it can be learned that high body mass index and insulin-independent diabetes mellitus are risk factors for developing DISH further supporting, though certainly not proving, that the lifestyle of ancient clergymen (sedentary work; abundance of food), may have predisposed them to develop DISH [36, 37].

Examination of the skeletal material with severe abnormalities suggests that DISH may have seriously affected the locomotor and probably also cardiopulmonary apparatus of individuals with this condition. For example, ankylosis of the thoracic cage forced the individual from grave 25 to ventilate by diaphragm contraction only and this would have led to restriction of pulmonary function and subsequent physical impairment. Furthermore, when the physiological range of motion of multiple bony joints from the axial and peripheral skeleton becomes limited due to surrounding soft tissue ossification, it is not unreasonable to suggest that affected individuals may have had clinical symptoms that are detectable by physical examination. The individual from grave 25 probably also suffered from restricted abduction and endorotation (estimated to be between 45-60 degrees for both maneuvers before ossified soft tissue impingement), in the left glenohumeral joint. Due to postmortem absence of the articular surface of the humeral head on the contralateral side, no right shoulder impingement could be estimated.

In conclusion, DISH may actually be a clinically relevant condition although presumably only so when the more advanced stages of the disease have been reached. Regarding the presently known clinical symptoms, the diagnosis DISH should be considered in patients of middle or advanced age with unexplainable back pain or peripheral arthralgia and/or restricted motion and should alert the physician for the presence of fracture dislocations in DISH patients complaining of back pain after relatively minor trauma [1].

Acknowledgments The authors would like to thank Joost Roelofs for his technical assistance during the acquisition of computed tomography data from the skeletal material.

\section{References}

1. Belanger TA, Rowe DE (2001) Diffuse idiopathic skeletal hyperostosis: musculoskeletal manifestations. J Am Acad Orthop Surg 9:258-267

2. Resnick D (1978) Diffuse idiopathic skeletal hyperostosis. AJR Am J Roentgenol 130:588-589

3. Maat GJR, Mastwijk RW, Van der Velde EA (1995) Skeletal distribution of degenerative changes in vertebral osteophytosis, vertebral osteoarthritis and DISH. Int J Osteoarchaeol 5:289-298

4. Resnick D, Niwayama G (1976) Radiographic and pathologic features of spinal involvement in diffuse idiopathic skeletal hyperostosis (DISH). Radiology 119:559-568

5. Julkunen H, Knekt P, Aromaa A (1981) Spondylosis deformans and diffuse idiopathic skeletal hyperostosis (DISH) in Finland. Scand J Rheumatol 10:193-203

6. Kim SK, Choi BR, Kim CG et al (2004) The prevalence of diffuse idiopathic skeletal hyperostosis in Korea. J Rheumatol 31:2032-2035

7. Weinfeld RM, Olson PN, Maki DD et al (1997) The prevalence of diffuse idiopathic skeletal hyperostosis (DISH) in two large American Midwest metropolitan hospital populations. Skeletal Radiol 26:222-225

8. Denko CW, Malemud CJ (2006) Body mass index and blood glucose: correlations with serum insulin, growth hormone, and insulin-like growth factor-1 levels in patients with diffuse idiopathic skeletal hyperostosis (DISH). Rheumatol Int 26:292-297 
9. Kiss C, Szilagyi M, Paksy A et al (2002) Risk factors for diffuse idiopathic skeletal hyperostosis: a case-control study. Rheumatology (Oxford) 41:27-30

10. Sarzi-Puttini P, Atzeni F (2004) New developments in our understanding of DISH (diffuse idiopathic skeletal hyperostosis). Curr Opin Rheumatol 16:287-292

11. Kiss C, O’Neill TW, Mituszova M et al (2002) Prevalence of diffuse idiopathic skeletal hyperostosis in Budapest, Hungary. Rheumatology (Oxford) 41:1335-1336

12. Canci A, Marchi D, Caramella D et al (2005) Coexistence of melorheostosis and DISH in a female skeleton from Magna Graecia (sixth century BC). Am J Phys Anthropol 126:305-310

13. Chhem RK, Schmit P, Faure C (2004) Did Ramesses II really have ankylosing spondylitis? A reappraisal. Can Assoc Radiol J 55:211-217

14. Crubezy E, Trinkaus E. Shanidar 1 (1992) A case of hyperostotic disease (DISH) in the middle Paleolithic. Am J Phys Anthropol 89:411-420

15. Russell AS (2004) Ankylosing spondylitis or DISH in ancient mummies. Can Assoc Radiol J 55:335

16. Rothschild BM (1987) Diffuse idiopathic skeletal hyperostosis as reflected in the paleontologic record: dinosaurs and early mammals. Semin Arthritis Rheum 17:119-125

17. Beyeler C, Schlapbach P, Gerber NJ et al (1992) Diffuse idiopathic skeletal hyperostosis (DISH) of the elbow: a cause of elbow pain? A controlled study. Br J Rheumatol 31:319-323

18. Ebo DG, Uytterhaegen PJ, Lagae PL et al (2005) Choking, sore throat with referred otalgia and dysphagia in a patient with diffuse idiopathic skeletal hyperostosis (DISH). Acta Clin Belg 60:98-101

19. Naik B, Lobato EB, Sulek CA (2004) Dysphagia, obstructive sleep apnea, and difficult fiberoptic intubation secondary to diffuse idiopathic skeletal hyperostosis. Anesthesiology 100:13111312

20. Hendrix RW, Melany M, Miller F et al (1994) Fracture of the spine in patients with ankylosis due to diffuse skeletal hyperostosis: clinical and imaging findings. AJR Am J Roentgenol 162:899-904

21. Houk RW, Hendrix RW, Lee C et al (1984) Cervical fracture and paraplegia complicating diffuse idiopathic skeletal hyperostosis. Arthritis Rheum 27:472-475

22. Fahrer H, Barandum R, Gerber NJ et al (1989) Pelvic manifestations of diffuse idiopathic skeletal hyperostosis (DISH): are they clinically relevant? Rheumatol Int 8:257-261
23. Schlapbach P, Beyeler C, Gerber NJ et al (1989) Diffuse idiopathic skeletal hyperostosis (DISH) of the spine: a cause of back pain? A controlled study. Br J Rheumatol 28:299-303

24. Meertens Institute, Koninklijke Nederlandse Akademie van Wetenschappen 2005

25. De Koning J (1997) Voorlopig verslag van de stratigrafische opgraving in de Pandhof van de Onze Lieve Vrouwekerk te Maastricht 1997. Cultural heritage from the City of Maastricht

26. Maat GJR, Panhuysen RGAM, Mastwijk RW (1999) Manual for the physical anthropological report. Barge's Anthropologica 6:150

27. Ciocci A (1987) Diffuse idiopathic skeletal hyperostosis (DISH) and situs viscerum inversus. Report of a single case. Clin Exp Rheumatol 5:159-160

28. Forestier J R-QJ (1950) Senile ankylosing hyperostosis of the spine. Ann Rheum Dis 9:321-330

29. Resnick D, Shapiro RF, Wiesner KB et al (1978) Diffuse idiopathic skeletal hyperostosis (DISH) [ankylosing hyperostosis of Forestier and Rotes-Querol]. Semin Arthritis Rheum 7:153-187

30. Tsukahara S, Miyazawa N, Akagawa $\mathrm{H}$ et al (2005) COL6A1, the candidate gene for ossification of the posterior longitudinal ligament, is associated with diffuse idiopathic skeletal hyperostosis in Japanese. Spine 30:2321-2324

31. Inamasu J, Guiot BH, Sachs DC (2006) Ossification of the posterior longitudinal ligament: an update on its biology, epidemiology, and natural history. Neurosurgery 58:1027-1039

32. Rogers J, Waldron T (2001) DISH and the monastic way of life. Int J Osteoarchaeol 11:357-365

33. Waldron T (1985) DISH at Merton Priory: evidence for a "new", occupational disease? Br Med J (Clin Res Ed) 291:1762-1763

34. Janssen HAM, Maat GJR (1999) Canons buried in the stiftskapel of the Saint Servaas Basilica at Maastricht. In: Barge's Anthropologica, vol 5. 2nd edn. pp 1-43

35. Panhuysen RGAM (2005) Demography and health in early medieval Maastricht. Prosopographical observations on two cemetaries. Academic dissertation

36. Bray GA, Bellanger T (2006) Epidemiology, trends, and morbidities of obesity and the metabolic syndrome. Endocrine 29:109-117

37. Daniels SR (2005) Regulation of body mass and management of childhood overweight. Pediatr Blood Cancer 44:589-594 